\title{
Innovation and Entrepreneurship Education and Practice of Student Community Based on Institutional Innovation
}

\author{
Liu Peng \\ xijing university \\ 56901090@qq.com
}

Keywords: Student community; Innovation and entrepreneurship; Practice; Institutional innovation

\begin{abstract}
In the great cause of revitalizing the country through science and education in the $21 \mathrm{st}$ century, the demand for high-quality, compound, innovative and entrepreneurial talents is increasing. Colleges and universities shoulder the heavy responsibility of cultivating a large number of high-quality and innovative talents. Whether higher education can cultivate talents with innovative spirit and creative ability to meet the needs of society is not only the prerequisite for economic and social development and progress, but also the key to the survival and development of higher education. This paper aims at innovation and entrepreneurship education is to improve the overall quality of educated, colleges and universities to strengthen the quality of education for college students, in particular, to highlight the quality of innovation and entrepreneurship, and the activities of college students' associations are important methods and effective ways to implement quality education. This paper proposes the characteristics and effects of college students' associations on innovation and entrepreneurship, and hopes to increase the importance of colleges and universities through innovation and entrepreneurship.
\end{abstract}

\section{Introduction}

In recent years, with the continuous deepening of institutional reforms and quality education in colleges and universities, college student organizations as an important carrier of campus culture have become more and more influential and attractive to college students, and student organizations have become increasingly important in the growth of college students. Looking at the development and changes in the number and types of student organizations, college student organizations are gradually forming a variety of types such as theoretical studies, academic science and technology, social practice, recreational sports, innovation and entrepreneurship. Among them, the pace of development of innovative entrepreneurial student clubs is particularly noticeable. On the one hand, with the development of higher education from the elitist to the popular, the employment situation of university students has become increasingly severe, coupled with the impact of the global financial crisis, the employment problem of college students has become the focus of public attention. It has become an important task for higher education to carry out innovation and entrepreneurship education in universities, support the development of innovation and entrepreneurship societies, and improve the students' ability of innovation and entrepreneurship. On the other hand, the innovative and entrepreneurial student community has received extensive attention from college students and the society due to the characteristics of adapting to the development of the times and helping to improve the innovative ability of college students. Therefore, it is of great social significance to seek effective development approaches for innovative and entrepreneurial colleges and universities.

\section{The Role of University Societies in Innovation and Entrepreneurship Education}

Students with common interests and social needs form university societies. The societies provide these students with an atmosphere of open learning and freestyle inquiry. In the community, students can learn from each other and progress together. The associations cultivate students' spirit of mutual collaboration and initiative exploration and innovation and play a very important role in 
improving students' innovation and entrepreneurship.

College societies create an atmosphere for innovation and entrepreneurship education

Judging from the model of education, college students are exposed to the concept of absolute belief in theoretical knowledge. Students' awareness of innovation and entrepreneurship is weak, and they are affected by the credit system in colleges and universities. Students can only complete corresponding credits according to their requirements. As a result, innovation and entrepreneurship education as a whole has formed a weak side[1]. College societies are the second classroom for students. The knowledge that students receive here comes from their own interests. Students with the same interests can find motivation to continue to generate interest here. The communities with common interests form a corporate culture in the long-term development. The expansion of the culture by members of the community not only helps foster the cultural awareness of innovation and entrepreneurship among the members of the community, but also facilitate the creation of an atmosphere of innovation and entrepreneurship education for members outside the community.

College societies cultivate students' spirit of innovation and entrepreneurship

University associations are free associations that are built up through interest. The behaviors of members in the associations are driven by interest. They are autonomous behaviors without external influences. Members can actively participate in community activities under the influence of common goals. And it can be united in action. In innovation and entrepreneurship, students solve problems through thinking about new paths. In the process of thinking, students' awareness of innovation is cultivated. At the same time, students are required to develop creative thinking and create superior projects. In the venture, members of the community win the fierce competition. Initiatives need to constantly challenge difficulties, and use imagination and subjective initiative to adapt to the situation in entrepreneurship.

University associations enrich students' knowledge structure of innovation and entrepreneurship.

Innovation and entrepreneurship require the accumulation of certain theoretical knowledge and practical experience. In other words, having knowledge has the corresponding tools to solve the problems in innovation and entrepreneurship. In innovation and entrepreneurship, the students of a community have a unique characteristic. Students come from different faculties and study different majors. Therefore, students can communicate with each other and develop professional knowledge in their respective fields. As a platform for innovation and entrepreneurship, students can use this platform to develop professional knowledge in their own fields. Students learn and enhance communication with each other, apply theoretical knowledge to practice, and enrich other students' professional knowledge[2]. The process of innovation and entrepreneurship is a process of constant learning and adaptation. Students make use of the community platform to make up for the knowledge that cannot be learned in classroom teaching. At the same time, students will increase their interest in learning and enrich their learning experience.

\section{The Characteristics of the Development of Innovation and Entrepreneurship Association in Colleges and Universities}

Fully expand the utility of college students' associations. College students' associations are student organizations whose students are voluntarily based on common interests and hobbies and who carry out their activities in accordance with the regulations. The activities of college student societies play an irreplaceable role in strengthening the construction of campus culture, training students' autonomous abilities, improving the overall quality of students, guiding students to adapt to society, and promoting the employment of students.

The student community has the characteristics of goal convergence and organizational dynamics, which is conducive to improving the overall quality of students.

Members of student organizations are students with similar similarities in interests, hobbies, specialties, and concepts, and they have a high level of enthusiasm for participation in community activities. Students' associations are dynamic, and each year the "more overlap" changes of freshmen and old students make it possible for the community to supplement "fresh blood" in a 
timely manner. Freshmen have a strong sense of freshness and initiative in community activities. According to their own interest and development vision, students adjust the orientation and convergence of community activities with the aim of giving full play to their strong points and cultivating their ability; the goals of individual members are converged and adjusted to make the group goals tend to be unified gradually. The consistent convergence of community goals provides conditions for the improvement of individual members ability and quality.

The student community has the characteristics of extensive content and openness to activities, which is conducive to training students' ability and advancing teaching reform in colleges and universities.

There are many kinds of college students' associations. Many scientific, managerial, literary and artistic associations are based on a wide range of cultural knowledge and are characterized by practical activities such as production, creation and invention. In order to cultivate students' thinking ability and hands-on ability, a series of activities such as academic research, scientific and technological inventions, cultural entertainment, social service, practice inspection and so on are carried out. Students are in favor of them. At the same time, the community activities closely contact the society, the content of the activities is more extensive, and the awareness of innovation is paid more attention in the activities, thus promoting the cultivation of the quality of the members of the community.

The community has the characteristics of form diversity, self-adjustment, is conducive to the promotion of students' physical and mental health, is a supplement to behavior management.

Because the psychological stage of college students is not yet fully mature, their mental abilities are generally weak. If there is no interpersonal communication and no "self" is found, psychological barriers are likely to appear. The relaxed and harmonious environment within the club organization and the more harmonious exchanges and contacts among the members can help them to establish good interpersonal relationships as soon as possible, creating a good opportunity for them to express themselves and publicize their individuality. At the same time, the management of students in universities is mainly reflected in classroom education and class management. The function of classroom education is limited, and the effect of class management is rather weakened. Furthermore, college students' time for extracurricular education is almost in loose state of management. Therefore, the relevant management system and activity charter of the student community can become intangible constraints and realize "doing nothing and govern", that is, affecting different student groups through the members of the community, and will eventually realize the students' "self-education, self-management, self service" to effectively make up for the management gap in colleges and universities.

\section{The Way for college Community to Carry out Innovation and Entrepreneurship Education}

\section{Organize the scientific guidance of excellent teachers}

The community innovation and entrepreneurship practice is a student-led activity. Considering the lack of students' theoretical knowledge and social practical experience, there is a need for professional guidance teachers to conduct scientific guidance. Colleges and universities need to arrange and guide their work according to the situation of teachers and the development of mass organizations. Association instructors provide general guidance on community culture. At the same time, they can help students introduce more resources according to the needs of the community's innovation and entrepreneurship. Instructors also provide certain constructive opinions on the organizational development and development planning of the community, train core members for the community[3].

\section{Organize community members to participate in various social practices}

The community is another classroom for practical education. Students are closely involved with their own practical ideas and interests to carry out various activities. At the same time, in order to strengthen the influence of the community in college students' innovation and entrepreneurship education, it is necessary to organize the associations to carry out various activities in a planned 
manner. Social practices are regularly carried out around the theme of entrepreneurship. Members of the community can exchange innovative ideas through practice. At the same time, through social practice activities, members of the community can enhance their practical ability. Societies should use their own advantages to open up space for social interaction and use social resources to provide students with a platform for subjective initiative and creativity. Social practice activities will highlight students' creative creativity. Students can closely integrate theory and practice to improve their overall quality.

\section{Combined with innovation and entrepreneurship education}

Although the innovation and entrepreneurial student community has developed rapidly, the level of holding activities has been uneven. The main reason is that training is not in place and professional guidance and communication are lacking. From the school's point of view, we must give full play to the advantages of entrepreneurial education activities, and improve the ability of community members to innovate and start businesses in various ways such as entrepreneurship training classes, featured lectures, and entrepreneurship lecture halls. At the same time, appropriate increase in funding and policy support efforts, the establishment of entrepreneurial laboratories and off-campus practice venues, to provide a strong guarantee for the training of community students innovative and entrepreneurial ability [3]. It is necessary to further improve the mechanism, strengthen management and service in the aspects of policy guarantee mechanism, funding guarantee mechanism, project management mechanism, and innovation incentive mechanism to promote the healthy development of innovation and entrepreneurship societies[4].

\section{Combined with entrepreneurial competition}

By participating in various innovative and entrepreneurial competitions, members of the student associations can learn from each other, find gaps, lack awareness, and stimulate the passion and fighting spirit of self-employment. At the same time, they are fully trained and tested in terms of personal qualities, leadership skills, team spirit and so on. This is crucial for the development of a student club. Regardless of the overall development of the team, or the development of team members, actively participating in the innovation and entrepreneurship competition is an effective way to promote the development of innovative and entrepreneurial student communities.

College community provide a new platform for students' innovation and entrepreneurship education. Students can use the bond of interest to achieve a common dialogue. At the same time, in the practice of consensus projects, students develop their own innovative awareness and social practice capabilities, which are of great significance for the completion of the goal of innovation and entrepreneurship education for college students. Colleges and universities should strengthen and improve the construction of college students' associations and give full play to the role of university associations in the innovation and entrepreneurship education of college students.

\section{Summary}

To improve the effectiveness of colleges and universities for innovative and entrepreneurial student organizations, we must also strengthen the guidance of teacher team building and implement a double tutor system. The school's full-time teachers serve as professional tutors, focusing on guiding students in innovative thinking training, innovative product research and development, and improvement of production processes; hiring outside school industry business managers and entrepreneurial experts and scholars to serve as outside entrepreneurship tutors, focusing on guiding students to develop professional practice ,Provide entrepreneurial policy consulting and corporate operations management knowledge and other content. As an educational model, innovation and entrepreneurship education emphasizes the role of both parties in teaching. It must start from the dual-subjects and eventually realize the goal of integration. Therefore, the innovation and entrepreneurial student community activities must be controlled at all times to ensure that the four are common, that is, teachers and students jointly conduct professional learning, jointly carry out innovative research, jointly conduct entrepreneurial practice, and jointly enhance the ability of innovation and entrepreneurship. 


\section{References}

[1] Patton D. Entrepreneurship: Globalization, Innovation and Development[J]. International Journal of Entrepreneurial Behavior \& Research, 2001, 7(5):205-206.

[2] Sun H. The 3-3-3 framework and 7P model for teaching creativity, innovation and entrepreneurship[J]. IEEE Engineering Management Review, 2012, 40(2):157-163.

[3] Shuming M A. The Role and Thinking of Training Model in Innovation and Entrepreneurship Education in the New Era[J]. Guide of Science \& Education, 2012.

[4] Confalone P N. Innovation and Entrepreneurship in the Chemical Enterprise[M]. 2014.

[5] Zhou H, Luo Y. Vigorous measures to promote the enforcement of the undergraduate training programs for innovation and entrepreneurship[J]. China Modern Educational Equipment, 2013.

[6] Niu G H, University F N. Reforming the Training Model to Promote Innovation and Entrepreneurship of Graduates in Economics and Management Specialty of Colleges and Universities[J]. Journal of Fuyang Normal University, 2015.

[7] Edwards-Schachter M, García-Granero A, Sánchez-Barrioluengo M, et al. Disentangling competences: Interrelationships on creativity, innovation and entrepreneurship[J]. Thinking Skills \& Creativity, 2015, 16:27-39.

[8] Xiao Z, Wei Z. Research of An Undergraduate Innovation and Entrepreneurship Training Program[J]. Atlantis Press, 2015.

[9] Zhang Y, University X. Integrating idea of innovation and entrepreneurship education into talent training process: a case study in Ningbo Polytechnic Institute[J]. Journal of Nanchang Institute of Technology, 2016.

[10] Cao J F, Hao Y J. Research on Innovation and Entrepreneurship Talent-Training Model for New Local Colleges[J]. 2016.

[11] Xie R J. Research on the practice teaching system as the goal of innovation and entrepreneurship ability cultivation[J]. Laboratory Science, 2016.

[12] Sui G, Liang B, Jia H. Study of the undergraduate student's innovation and entrepreneurship training strategy[C]// Society of Photo-Optical Instrumentation Engineers. Society of Photo-Optical Instrumentation Engineers (SPIE) Conference Series, 2017:107.

[13] Wang X L, Teng W Z, Liu Y. Training Program of Professional Master's Degree in the Background of Innovation and Entrepreneurship[J]. Education Teaching Forum, 2017.

[14] Fang J J, Liu Z X. Research on the Ways of Training Talents of University Innovation and Entrepreneurship[J]. Education Teaching Forum, 2018. 